EGU2020-21636

https://doi.org/10.5194/egusphere-egu2020-21636

EGU General Assembly 2020

(c) Author(s) 2020. This work is distributed under

the Creative Commons Attribution 4.0 License.

\title{
Sea Surface Salinity trends in the Mediterranean and Black Seas from 10 years of SMOS measurements
}

\author{
Estrella Olmedo ${ }^{1}$, Verónica González-Gambau ${ }^{1}$, Antonio Turiel ${ }^{1}$, Cristina González-Haro ${ }^{1}$, Justino \\ Martínez ${ }^{1}$, Carolina Gabarró ${ }^{1}$, Aida Alvera-Azcárate ${ }^{2}$, Marilaure Grégoire ${ }^{2}$, and Marie-Helene Rio ${ }^{3}$ \\ ${ }^{1}$ BEC \& Institute of Marine Sciences, CSIC. P. Marítim de la Barceloneta, 37-49, 08003 Barcelona, Spain \\ ${ }^{2}$ University of Liège Allée du 6 Août, 17 Sart Tilman, Liège 4000, Belgium \\ ${ }^{3}$ European Space Agency, ESA-ESRIN. Largo Galileo Galilei 1 Casella Postale 6400044 Frascati, Italy
}

The monitoring of the sea surface salinity (SSS) in the semi-enclosed seas has a significant impact in the study of the climate change. In those basins the oceanographic processes occur at higher temporal scales than in the open ocean, and therefore, trends and anomalies can be detected before. The Mediterranean Sea is a strongly evaporative basin (evaporation exceeds the precipitation and river run-off). Converserly, in the Black Sea the river run-off and precipitation exceeds the evaporation. Based on a 4-year time series (2015-2019) of SMAP SSS, a recent study has shown that there is an increase of the salinity in the Eastern Mediterranean [Grodsky, et al. 2019]. On the other hand, the Black Sea exhibits a rich variability in space and time from (sub)mesoscale to larger scales (interannual and larger) that needs to be appropriately taken into account when trying to identify long-term trends.

We present new estimates of SSS trends in the Mediterranean and Black Seas. These estimations are based on 10-year series obtained from the European Soil Moisture and Ocean Salinity (SMOS) mission. Two new SMOS SSS regional products have been generated. On the one hand, we have generated a new realease of SMOS SSS regional product for the Mediterranean Sea. The new release of SMOS SSS regional product for the Mediterranean Sea provides better coverage in the Eastern Mediterranean than the previous version of this product (see [Olmedo et al 2018]). The new dedicated SMOS SSS product for the Black Sea has been developed under the currently ongoing ESA EO4BIS contract (An Earth Observation Data for Science and Innovation in the Black Sea). The Black Sea and the Eastern Mediterranean are strongly affected by Radio Frequency Interferences (RFI) sources, which hamper the salinity retrieval. We have applied specific methodologies to diminish the strong RFI effects in these two basins [González-Gambau et al 2017]. The new realase of these two SMOS SSS regional products will be available soon in the Barcelona Expert Center website (http://bec.icm.csic.es ).

At this conference we will present the methodologies that we have used for the generation of both regional SMOS SSS products. We will also present a quality assessment over the two regions consisting of comparing with in situ salinity measurements. Finally, we will show the SSS trends that are obtained in the different basin (and sub-basins) as well as the significance of the 
results with respect to the accuracy of the new SMOS SSS products.

[Grodsky, et al. 2019] Grodsky S., et al. (2019), "Eastern Mediterranean salinification observed in satellite salinity from SMAP mission", Journal of Marine Systems, 198

[Olmedo et al 2018] Olmedo, E, et al. , (2018) "Improving SMOS Sea Surface Salinity in the Western Mediterranean Sea through Multivariate and Multifractal Analysis," Remote sensing, 10(3), 485.

[González-Gambau et al 2017] González-Gambau, V. et. al, (2017), "Improvements on calibration and image reconstruction of SMOS for salinity retrievals in coastal regions," in IEEE Journal of Selected Topics in Applied Earth Observations and Remote Sensing, 10, 7, 3064-3078 